\title{
POTENSI ANTIJAMUR EKSTRAK METANOL DAUN MANGROVE RHIZOPORA MUCRONATA TERHADAP JAMUR CANDIDA ALBICANS DAN ASPERGILLUS NIGER
}

\section{POTENTIAL ANTIFUNGI EXTRACT METHANOL LEAF MANGROVE RHIZOPORA MUCRONATA ON FUNGI CANDIDA ALBICANS AND ASPERGILLUS NIGER}

\author{
Usman $^{2}$, Vega Zulia Putri Adi ${ }^{1 *}$, \\ ${ }^{1}$ Program Studi Pendidikan Kimia, FKIP UNMUL, Samarinda Kalimantan Timur, Indonesia \\ ${ }^{2}$ Laboratorium Pendidikan Kimia, FKIP UNMUL, Samarinda \\ Kalimantan Timur, Indonesia \\ *email: zuliave1@gmail.com
}

Submit : 10 Oktober 2017 Accepted : 06 November 2017

\begin{abstract}
Candida Albicans and Aspergillus Niger are some of the infectious fungi. Empirically bark, flower, root and mangrove leaves Rhizophora mucronata can be a hepatitis drug. This study aims to determine the antifungal potential of methanol extract of Rhizophora mucronata leaves to Candida Albicans and Aspergillus Niger fungus. Chemical test results that have been done previously are alkaloids, Flavanoid, triterpenoids, saponins, tannins and hydroquinone phenols. The antifungal test was performed by agar diffusion method on Potatos Dextrose Agar (PDA) medium and paper disc.Paper disc soaked in methanolic extract of Rhizophora mucronatapada leaf concentration 1000 ppm, 800 ppm, 600 ppm, 400 ppm and 200 ppm. The positive control solution used ketokenazole drug and negative control using aquades with incubation period of $3 \times 24$ hours. The results did not prove that Rhizophora mucronata leaf methanol extract was effective to inhibit antifungal activity against Candida Albicans and Aspergillus Niger fungi.
\end{abstract}

Keywords: Anti-Fungi, Phytochemistry, Rhizophora mucronata Leaves, Candida Albicans, Aspergillus Niger.

\section{PENDAHULUAN}

Rumusan masalah dari penelitian ini yaitu apakah ekstrak metanol daun Mangrove Rhizopora mucronata mampu menghambat pertumbuhan jamur Candida albicans dan Aspergilus niger?

RhizoporaMucronata atau sering dikenal dengan nama bakau hitam ialah namasekelompok tumbuhan di hutan mangrove dari genus Rhizophora dan famili Rhizophoraceae. Berdasarkan identifikasiKusmana [1] di Teluk Bintuni, Irian jaya, R. mucronata mampu tumbuh hingga mencapai diameter $35 \mathrm{~cm}$ dengan tinggi $30 \mathrm{~m}$. Batang berdiri tegak, tidak berlekuk, tidak berpilin, dan tidak berbenjol.Rhizophora sp. Merupakan salah satu jenis tanaman mangrove, yaitu kelompok tropis yang bersifat halophytic atau toleran terhadap garam. Mangrove memiliki kemampuan khusus untuk beradaptasi dengan kondisi lingkungan yang ekstrim, seperti kondisi tanah yang tergenang, kadar garam tinggi serta kondisi tanah yang kurang stabil. Kondisi lingkungan seperti itu menyebabkan beberapa jenis mangrove mengembangkan mekanisme yang memungkinkan secara aktif mengeluarkan garam dari jaringan, sementara yang lainnya mengembangkan sistem akar napas untuk membantu memperoleh oksigen bagi sistem perakarannya [2].

Penelitian ini dilakukan untuk mengetahui kemampuan ekstrak metanol daun Mangrove Rhizopora mucronata dalam menghambat pertumbuhan jamur Candida albicans dan Aspergilus niger.

Rhizophora mucronata banyak dimanfaatkan dalam bidang kesehatan karena memiliki khasiat untuk menyembuhkan beberapa penyakit seperti beri-beri, haematoma, hepatitis dan borok [3]. Mangrove kaya akan senyawa steroid, saponin, flavonoid dan tannin. Senyawa saponin dari tumbuhan adalah glikosida dari triterpene dan steroid, yang larut dalam air dan mempunyai kemampuan membentuk buih sabun bila dikocok di air. Penggunaan saponin sebagai deterjen alam dan racun ikan telah dikenal oleh masyarakat tradisional.Selain itu, Harwoko dan 
Utami [4] telah menunjukkan dalam penelitiannya bahwa Fraksi n-heksana: kloroform dari ekstrak metanol kulit batang R. mucronata memiliki aktivitas sitotoksik pada sel kanker myeloma dengan nilai $\mathrm{IC}_{50}$ sebesar $15 \mu \mathrm{g} / \mathrm{mL}$ serta kandungan kimia dalam fraksi tersebut adalah senyawa flavonoid dan terpenoid. Diastuti dan Suwandri (2009), Menyatakan bahwa ekstrak metanol kulit batang R. mucronata juga mengandung senyawa terpenoid.

Antijamur adalah senyawa yang digunakan untuk pengobatan penyakit infeksi yang disebabkan oleh jamur [5]. Menurut Sufriadi ada beberapa faktor yang mempengaruhi efektivitas dari suatu antimikroba yaitu konsentrasi, suhu, waktu, sifat fisik, dan kimia subtrat ( $\mathrm{pH}$, kadar air, jenis, dan jumlah zat terlarut). Adanya aktivitas antimikroba dapat dilihat dari terbentuknya zona bening disekitar kertas cakram.Aktivitas antimikroba secara in vitro dapat digunakan untuk menentukan potensi suatu zat antimikroba dalam larutan, konsentrasinya dalam cairan badan atau jaringan, dan kepekaan suatu mikroba terhadap konsentrasi-konsentrasi obat yang dikenal [6].

\section{METODOLOGI PENELITIAN}

Prosedur pengambilan sampel

Sampel mangrove yang digunakan adalah bagian jaringan daun mangrove jenis Rhizophora mucronata yang diambil dari kawasan mangrove di Bontang Kalimantan Timur.Penelitian ini dilakukan bertujuan untuk mengetahui kemampuan ekstrak daun mangrove Rhizophora mucronata dalam menghambat pertumbuhan jamur.

1. Persiapan Sampel dan Ekstraksi

Mencuci dan mengeringkan bahan tanpa terkena sinar matahari langsung agar senyawasenyawa yang terkandung dalam sampel tidak rusak oleh sinar UV matahari.Sampel yang telah kering dihaluskan dan dimaserasi dengan pelarut metanol. Ekstraksi daun Rhizophora mucronata Lamk.Dilakukan dengan metode maserasi berdasarkan tingkat kepolaran pelarut. Perbandingan berat sampel dengan pelarut pada saat maserasi adalah 1:4 (500 g : $2000 \mathrm{ml})$. Maserasi dilakukan dengan menggunakan pelarut metanol selama $1 \times 24$ jam dengan pengulangan sebanyak tiga kali.Fitrat dari rendamen metanol kemudian disaring dengan menggunakan kertas saring dan kemudian diuapkan menggunakan rotary evaporator pada suhu $40^{\circ} \mathrm{C}$, hingga didapatkan ekstrak kasar (pasta) berwarna hijau pekat.

2. Uji golongan fitokimia

a. Alkaloid

Sebanyak $5 \mathrm{~mL}$ ekstrak dimasukkan ke dalam tabung reaksi ditambahkan $2 \mathrm{~mL} \mathrm{HCl}$ pekat, kemudian dimasukkan $1 \mathrm{~mL}$ larutan Dragendorff. Perubahan warna larutan menjadi jingga atau merah menunjukkan adanya senyawa alkaloid.

b. Flavonoid

Sebanyak $1 \mathrm{~mL}$ ekstrak dimasukkan ke dalam tabung reaksi, kemudian ditambahkan beberapa tetes natrium hidroksida encer $(\mathrm{NaOH} 1 \%)$, jika pada saat penambahan terbentuk warna kuning menunjukkan adanya senyawa flavonoid.

c. Triterpenoid atau steroid

Sebanyak $1 \mathrm{~mL}$ ekstrak dimasukkan ke dalam tabung reaksi. Identifikasi dilakukan dengan menggunakan campuran asam asetat anhidrat dan asam sulfat pekat yang biasa dikenal dengan pereaksi LiebermannBarchard. Pada pengujian ini 10 tetes asam asetat anhidrat dan 2 tetes asam sulfat pekat ditambahkan secara berurutan ke dalam sampel. Kemudian sampel dikocok dan dibiarkan beberapa menit. Reaksi yang terjadi diikuti perubahan warna, jika terlihat warna merah-ungu menunjukkan positif triterpenoid dan jika terlihat warna hijaubiru menunjukkan positif steroid.

d. Saponin

Sebanyak $1 \mathrm{~mL}$ ekstrak dimasukkan ke dalam tabung reaksi dan ditambahkan $10 \mathrm{~mL}$ aquades panas dan dikocok kuat-kuat selama 10 detik jika menghasilkan busa yang stabil setinggi 1$10 \mathrm{~cm}$ maka menunjukkan adanya senyawa saponin.

4. Uji antijamur

a. Metode uji antijamur

Metode yang digunakan dalam pengujian ini yaitu metode difusi cara cakram untuk mengetahui efektivitas antijamur dengan mengamati daerah hambatan.

b. Pembuatan larutan Uji

Pembuatan suspensi fungi uji dilakukan dengan memasukkan 1 ose fungi Candida albicans dan Aspergillus 
Niger ke dalam tabung reaksi yang telah berisi $\mathrm{NaCl} \quad 0,9 \%$ sebanyak $3 \mathrm{ml}$, kemudian divortex hingga homogen ditandai dengan cairan berubah menjadi keruh.

c. Pembuatan Larutan Kontrol

Larutan kontrol adalah larutan yang digunakan sebagai pembanding antara larutan kontrol positif, larutan kontrol negatif dan berbagai jenis ekstrak daun dan akar.Larutan kontrol positif digunakan sebagai tolak ukur penentuan ekstrak memiliki potensi antifungi, jika daya hambat ekstrak melebihi atau mendekati dari nilai kontrol positif maka ekstrak tersebut berpotensi sebagai antifungi.Pembuatan larutan kontrol positif yang digunakan adalah larutan Ketoconazole untuk uji antifungi dengan konsentrasi 1000 ppm. Larutan Ketoconazole 1000 ppm dibuat dengan menimbang 2,841 mg serbuk Ketoconazole dalam labu ukur $100 \mathrm{~mL}$ dan ditambahkan DMSO hingga batas tanda. Kemudian dikocok hingga larut (Larutan A). Setelah itu dipipet sebanyak $1 \mathrm{~mL}$ dan dimasukkan ke dalam labu ukur $5 \mathrm{~mL}$ lalu ditambahkan DMSO hingga volumenya $5 \mathrm{~mL}$ (Larutan B). Kemudian dari larutan B dipipet $1 \mathrm{~mL}$ ke dalam labu ukur $5 \mathrm{~mL}$ dan dicukupkan volumenya dengan DMSO hingga batas tanda (Larutan C). Terakhir dipipet $1 \mathrm{~mL}$ larutan C dalam labu ukur $5 \mathrm{~mL}$ kemudian dicukupkan volumenya dengan DMSO.Larutan D adalah Ketoconazole 1000 ppm.Larutan kontrol negatif merupakan faktor koreksi dengan menggunakan pelarut aquades.

d. Pengujian Antijamur

Hal pertama yang harus dilakukan yaitu mengambil ekstrak Daun dan Akar Mangrove dalam vial sebanyak 1000 ppm, 800 ppm, 600 ppm, 400 ppm dan 200 ppm dimasukkan kedalam eppendorf yang berisi larutan methanol $40 \mu \mathrm{l}$ lalu dihomogenkan dengan menggunakan vortex. Larutan methanol yang mengandung ekstrak diambil $30 \mu \mathrm{l}$ diteteskan pada paper disc.Suspensi $200 \mu$ l dimasukkan ke dalam botol yang berisi $20 \mathrm{ml}$ medium PDA, digoyanggoyangkan \pm 1 menit hingga homogen.Setelah homogen dituang kedalam cawan petri dan dibiarkan memadat.Setelah memadat meletakkan paper disc pada permukaan medium.Inkubasikan pada suhu ruangan selama 3X24 jam, untuk mengetahui pengamatan zona hambat yang terbentuk.

\section{HASIL DAN PEMBAHASAN}

Penelitian ini dilakukan bertujuan untuk mengetahui kemampuan ekstrak daun mangrove Rhizophora mucronata dalam menghambat pertumbuhan jamur. Uji aktivitas antijamur dilakukan terhadap dua jamur Candida albicans dan Aspergillus niger. Adapun dari penelitian sebelumnya yang telah dilakukan, ekstrak metanol akar mangrove ini diperoleh dari sampel daun mangrove.

Ekstraksi daun Rhizophora mucronata Lamk.Dilakukan dengan metode maserasi berdasarkan tingkat kepolaran pelarut. Perbandingan berat sampel dengan pelarut pada saat maserasi adalah 1:4 (500 g : $2000 \mathrm{ml})$. Maserasi dilakukan dengan menggunakan pelarut metanol selama 1x24 jam dengan pengulangan sebanyak tiga kali. Pengulangan maserasi ini dilakukan untuk mengikat sisa senyawa metabolit sekunder yang mungkin masih tertinggal pada serbuk sampel yang direndam.Fitrat dari rendamen metanol kemudian disaring dengan menggunakan kertas saring dan kemudian diuapkan menggunakan rotary evaporator pada suhu $40^{\circ} \mathrm{C}$, hingga didapatkan ekstrak kasar (pasta) berwarna hijau pekat.

Uji fitokimia pada ekstrak daun mangrove Rhizopora mucronata, hal ini dilakukan untuk mengetahui kandungan senyawa yang terdapat pada sampel tersebut.Berdasarkan pada percobaan, dihasilkan hampir semua uji menunjukkan hasil positif, terkecuali pada uji steroid.Robinson dalam Naiborhu [7] mengatakan bahwa salah satu fungsi flavonoid dari tumbuhan adalah sebagai kerja antimikroba dan antivirus.Senyawa flavonoid dapat merusak membran sitoplasma yang dapat menyebabkan bocornya metabolit penting dan menginaktifkan sistem enzim bakteri.Kerusakan ini memungkinkan nukleotida dan asam amino merembes keluar dan mencegah masuknya bahan - bahan aktif ke dalam sel, keadaan ini dapat menyebabkan kematian bakteri. Hasil positif uji alkaloid sampel daun mangrove Rhizopora mucronata dengan menggunakan pereaksi wagner terbentuk endapan coklat. Pereaksi selanjutnya yaitu menggunakan asam sulfat 
$\left(\mathrm{H}_{2} \mathrm{SO}_{4}\right)$.Pada uji ini sampel daun Rhizophora mucronata menunjukkan perubahan warna menjadi kuning merah/coklat, maka sampel dikatakan positif mengandung senyawa flavonoid.Hasil uji triterpenoid dan steroid ditunjukkan dengan timbulnya warna merah jika positif triterpenoid dan timbul warna biru atau ungu jika positif steroid.Pada hasil uji menggunakan sampel daun Rhizophora mucronata Lamk.dapat dilihat bahwa sampel positif mengandung senyawa steroid. Hasil positif dari uji saponin pada sampel daun Rhizophora mucronata ditunjukkan dengan terbentuknya busa yang stabil tidak kurang dari 10 menit setinggi $3 \mathrm{~cm}$ dan tidak hilang pada penambahan satu tetes HCL $2 \mathrm{~N}$. Hasil positif untuk uji tanin ditunjukkan dengan perubahan warna menjadi hijau kehitaman. Sampel daun Rhizophora mucronata yang diujikan positif mengandung tanin.

Table 1. Hasil uji komponen aktif ekstrak kasar daun bakau hitamRhizophora mucronata

\begin{tabular}{|c|c|c|c|c|}
\hline Uji & $\begin{array}{l}\text { Ekstrak } \\
\text { metanol }\end{array}$ & Parameter & $\begin{array}{c}\text { Ekstrak } \\
\text { Air }\end{array}$ & Parameter \\
\hline \multicolumn{5}{|l|}{ Alkaloid } \\
\hline a. Dragendroff & + & Terbentuk endapan jingga & - & $\begin{array}{l}\text { Tidak terbentuk endapan } \\
\text { jingga }\end{array}$ \\
\hline b. Meyer & - & $\begin{array}{c}\text { Tidak terbentuk endapan } \\
\text { putih }\end{array}$ & - & $\begin{array}{c}\text { Tidak terbentuk endapan } \\
\text { putih }\end{array}$ \\
\hline c. Wagner & + & Terbentuk endapan coklat & - & $\begin{array}{l}\text { Tidak terbentuk endapan } \\
\text { coklat }\end{array}$ \\
\hline Tanin & + & Warna hijau kehitaman & + & Warna hijau kehitaman \\
\hline Saponin & + & Busa stabil & + & Busa stabil \\
\hline $\begin{array}{c}\text { Fenol } \\
\text { hidrokuinon }\end{array}$ & + & Warna hijau biru & + & Warna hijau biru \\
\hline Flavanoid & + & Warna kuning & + & Warna merah \\
\hline Steroid & - & $\begin{array}{l}\text { Tidak terjadi perubahan } \\
\text { warna }\end{array}$ & - & $\begin{array}{l}\text { Tidak terjadi perubahan } \\
\text { warna }\end{array}$ \\
\hline Triterpenoid & + & $\begin{array}{c}\text { Lapisan permukaan } \\
\text { berwarna merah kecoklatan }\end{array}$ & + & $\begin{array}{c}\text { Lapisan permukaan } \\
\text { berwarna merah kecoklatan }\end{array}$ \\
\hline
\end{tabular}

Berdasarkan uji laboratorium, hasil dari uji aktivitasantijamur menunnjukkan bahwaekstrak metanol daun mangrove Rhizophora mucronata pada konsentrasi 200 ppm, 400 ppm, 600 ppm,
800 ppm dan 1000 ppm tidak memiliki aktivitas antijamur terhadap jamur Candida albicans dan Aspergillus nigeryang ditandai dengan tidak terbentukknya zona hambat.

Tabel 2. Hasil Uji Potensi Antijamur Ekstrak Metanol Buah MangroveRhizophora mucronata

\begin{tabular}{|c|c|c|c|c|c|}
\hline \multirow{3}{*}{ Jamur } & \multicolumn{5}{|c|}{ Diameter Zona Hambat Jamur (mm) } \\
\hline & \multicolumn{5}{|c|}{$\begin{array}{c}\text { Konsentrasi Ekstrak Buah Mangrove } \\
\text { Rhizophora mucronata }\end{array}$} \\
\hline & $200 \mathrm{ppm}$ & $400 \mathrm{ppm}$ & $600 \mathrm{ppm}$ & $800 \mathrm{ppm}$ & $1000 \mathrm{ppm}$ \\
\hline $\begin{array}{l}\text { Candida } \\
\text { Albicans }\end{array}$ & $6 \mathrm{~mm}$ & $6 \mathrm{~mm}$ & $6 \mathrm{~mm}$ & $6 \mathrm{~mm}$ & $6 \mathrm{~mm}$ \\
\hline $\begin{array}{l}\text { Aspergillus } \\
\text { Niger }\end{array}$ & $6 \mathrm{~mm}$ & $6 \mathrm{~mm}$ & $6 \mathrm{~mm}$ & $6 \mathrm{~mm}$ & $6 \mathrm{~mm}$ \\
\hline
\end{tabular}




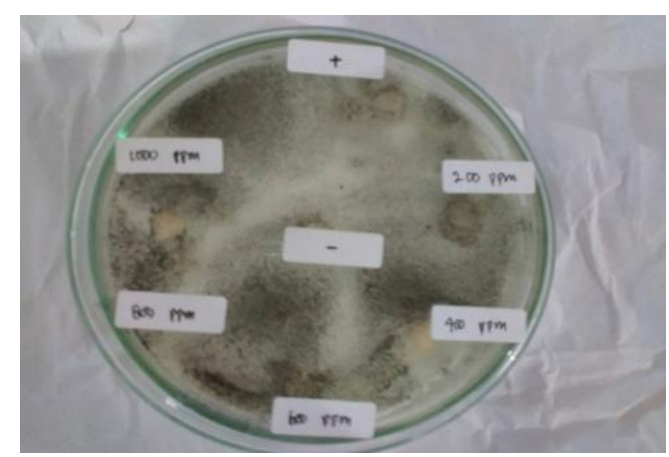

(a)

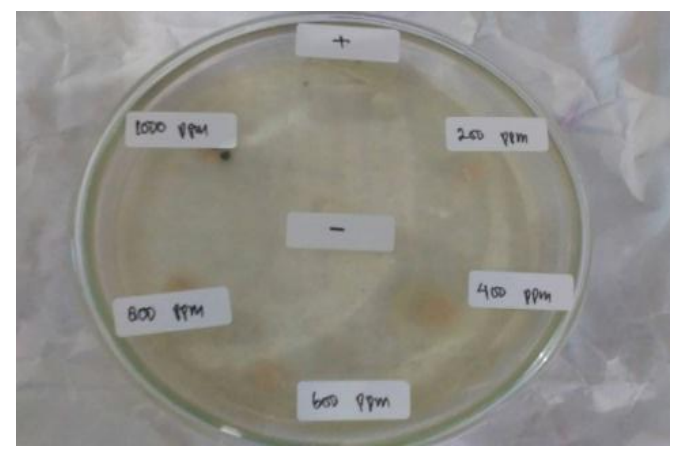

( b )

Gambar 1. Hasil uji antijamur dari daun mangrove Rhizopora mucronata terhadap jamur: (a). Candida Albicans dan (b). Aspergillus Niger

Setelah waktu inkubasi 3x24 jam, peneliti mengamati keadaan paper disk didalam cawan petri.Adapun hasil penelitian ini, ternyata tidak terdapat aktivitas antijamur yang ditandai dengan tidak ditemukannya zona hambat terhadap jamur Candida Albicans maupun Aspergillus Niger.Konsentrasi hambat minimum (KHM) adalah konsentrasi minimum dari suatu zat antimikroba yang dapat menghambat pertumbuhan bakteri lebih dari $99 \%$.Suatu zat dapat dikatakan mempunyai aktivitas yang tinggi apabila dengan konsentrasi yang rendah tetapi mempunyai daya hambat yang besar berdasarkan Coyle 2005 dalam Anak Agung 2013. Berdasarkan hasil yang diperoleh (lihat lampiran dapat dikatakan bahwa tidak terdapatnya zona hambat pada kontrol positif, kontrol negatif maupun sampel dengan beberapa variasi tersebut dikarenakan kurang besarnya konsentrasi hambat yang diberikan, karena minimal untuk uji antijamur konsentrasi yang dibutuhkan yaitu $\pm 10.000 \mathrm{ppm}$ pada sampel dan kontrol positif maupun negatif. Adapun beberapa faktor lain yang juga dapat mempengaruhi hasil yang kurang maksimal yaitu kurang sterilnya area uji antijamur, kurang baiknya pemahaman mengenai tatacara dalam melakukan uji antijamur oleh praktikan itu sendiri dan juga kurang tepatnya dalam menentukan konsentrasi sampel dan kontrol positif maupun kontrol negatifnya.

\section{KESIMPULAN}

Berdasarkan hasil penelitian dan pembahasan dapat diambil kesimpulan bahwa ekstrak metanol daun mangrove Rhizopohora mucronata pada varian $200 \mathrm{ppm}, 400 \mathrm{ppm}, 600$ ppm, 800 ppm dan 1000 ppm tidak menunjukkan adanya aktivitas antijamur pada jamur Candida Albicans dan Aspergillus Niger.

\section{SARAN}

Perlu penelitian lebih lanjut dengan cara menaikkan konsentrasi ekstrak metanol daun mangrove Rhizophora mucronata.Dalam pelaksanaan penelitian selanjutnya diharapkan dapat meningkatkan kesterilan alat, bahan maupun kondisi area pengujian.

\section{DAFTAR PUSTAKA}

[1] Kusmana, dkk. 2003. Hutan Mangrove Fungsi dan Manfaatnya. Fakultas Kehutanan IPB: Bogor.

[2] Setyawan, A.D. 2002. Ekosistem Mangrove sebagai Kawasan PeralihanEkosistem Perairan Tawar dan Perairan Laut. Enviro 2 (1): 25-40.

[3] Kordi, M. G. H. K.. 2012. Ekosistem Mangrove Potensi, Fungsi dan Pengelolaan. Rineka Cipta: Jakarta.

[4] Harwoko dan E. D. Utami. 2010. Aktivitas Sitotoksik Fraksi n-Heksana: Kloroform dari Ekstrak Metanol Kulit Batang Mangrove (Rhizopora mucronata) pada sel kenker Myeloma. Majalah Obat Tradisional 15(2): 51-55.

[5] Siswandono dan Soekardjo, B., (2000).Kimia Medisinal.Edisi 2. Surabaya: Airlangga University Press. hal. 291.303 
[6] Jawetz, dkk. 1980. Mikrobiologi Kedokteran. Penerbit Buku Kedokteran EGC: Jakarta.

[7] Robinson T. 1995. Kandungan Organik Tumbuhan Tinggi. Edisi keenam. Padmawinata $\mathrm{K}$, penerjemah. Bandung (ID): ITB. Terjemahan dari: The organic constituents of higer plants. 